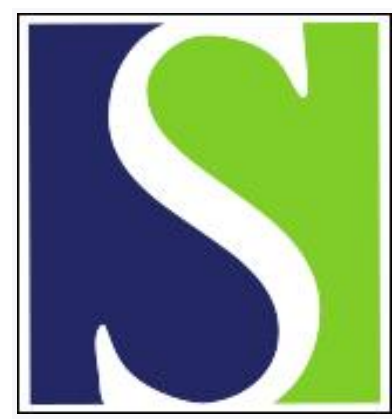

Scand J Work Environ Health 1987;13(2):118-123

https://doi.org/10.5271/sjweh.2072

Issue date: Apr 1987

Mortality of workers compensated for silicosis during the period 1959-1963 in the Veneto region of Italy.

by Zambon P, Simonato L, Mastrangelo G, Winkelmann R, Saia B, Crepet M

This article in PubMed: www.ncbi.nlm.nih.gov/pubmed/3602965

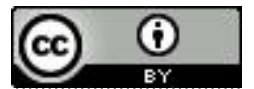




\title{
Mortality of workers compensated for silicosis during the period 1959-1963 in the Veneto region of Italy
}

\author{
by Paola Zambon, MD, ${ }^{1}$ Lorenzo Simonato, ${ }^{2}$ Giuseppe Mastrangelo, MD, ${ }^{1}$ \\ Regina Winkelmann, ${ }^{2}$ Bruno Saia, MD, ${ }^{1}$ Massimo Crepet, MD'
}

\begin{abstract}
ZAMBON P, SIMONATO L, MASTRANGELO G, WINKELMANN R, SAIA B, CREPET M. Mortality of workers compensated for silicosis during the period 1959-1963 in the Veneto region of Italy. Scand $J$ Work Environ Health 13 (1987) 118-123. After reports appeared from other countries indicating an excess risk of lung cancer among silicotics, a cohort of workers compensated for silicosis during the period 1959-1963 in the Veneto region of Italy was constructed and followed for mortality through 1984. The results of the study showed a large mortality excess for infectious diseases (180 observed versus 9.5 expected), due to silicotuberculosis, and for diseases of the respiratory system (270 observed versus 33.5 expected) due to silicosis. An elevated standardized mortality ratio of 239 (70 observed versus 29.3 expected) from lung cancer was also detected. An increasing pattern was observed with time since first exposure, while the relationship with employment category and duration of exposure was less clear-cut. The lung cancer excess was also strongly associated with cigarette smoking, there being a dose-response relationship with daily cigarette consumption. The study confirms the results from other epidemiologic studies on silicotics which show this pathological condition to be associated with increased lung cancer mortality.
\end{abstract}

Key terms: lung cancer, silica, smoking.

The question of whether exposure to silica dust may entail a carcinogenic risk for the lung in addition to its well-known effects on pulmonary parenchyma was reopened recently after a long period during which the epidemiologic data available have been considered to provide rather negative evidence for this association. Goldsmith et al (6) reviewed the experimental and human studies and concluded that the available evidence is suggestive of an association between lung cancer and exposure to silica. A similar review by Heppleston (7) arrived at opposite conclusions, exonerating silica itself from a carcinogenic role.

The mortality of workers compensated for silicosis has been recently investigated in Sweden (14), Canada (5), Finland (8), and Italy (9). These studies consistently report an elevated mortality for lung cancer, which is however difficult to interpret in relation to the possible association between exposure to silica dust and lung cancer risk. In 1982 we reported (16) the results of a historical follow-up, through 31 December 1980 , of a cohort of workers compensated for silicosis during the period 1959-1963 in the Veneto region of Italy.

The Veneto region (northeast Italy) presents one of the highest rates of silicosis in Italy due to the fact that, particularly in the past, a significant proportion of the

1 Center of Environmental Carcinogenesis of the University of Padova, Via Facciolati, 71, 35100 Padova, Italy.

2 International Agency for Research on Cancer, 150 Cours Albert-Thomas, 69372 Cedex 08, France.

Reprint requests to: Dr L Simonato, International Agency for Research on Cancer, 150 Cours Albert-Thomas, F-69372 Lyon Cedex 08, France. male working population has been employed in mines, tunnels, and quarries in this and other regions of Italy and also abroad. Considering the poor work conditions in the first half of the century, these workers are likely to have been exposed to high levels of silica dust.

The present paper improves and extends the followup study to 31 December 1984, and investigates whether workers compensated for silicosis are at higher risk of death than the general population, particular attention being given to tubercolosis, silicotuberculosis, nonmalignant respiratory diseases, and lung cancer.

\section{Subjects and methods}

The members of the study population were all newly compensated cases of silicosis among residents in the Veneto region in the northeast part of Italy (population in 1980, 4296545 ) during the period January 1959 - 31 December 1963. The cases were ascertained through the archives of the seven provincial offices of the National Institute for Compensation of Occupational Diseases.

The two major criteria for compensation were a radiological diagnosis of silicosis and an occupational history of exposure to silica. Only cases of silicosis have been included in the cohort. Two workers compensated for asbestosis during the same period were excluded.

Included in the study were 157 persons compensated after working as miners in Belgium. As those who have worked in other European countries are not registered by the Institute for Compensation of Occupational Dis- 
eases, it is not possible to evaluate with precision to what extent the loss of such cases affects the completeness of the cohort, but, according to estimates from the Institute, their number should not exceed 100 .

Complete occupational histories for the period involving exposure to silica dust were available for most of the cases $(88 \%$ ) from the archives of the aforementioned institute. When missing, the information was supplemented by the clinical records of the hospitals in which the silicosis had been diagnosed, mainly the Institute of Occupational Medicine of the University of Padova and the General Hospital in Belluno.

For $31(2.4 \%)$ workers (included in the cohort) the type of exposure remained unknown, and for $8(0.6 \%)$ the duration of exposure to silica was not reported. The occupational history was not updated after the date of compensation, and thus we cannot exclude some underestimation of duration of exposure in our data.

Out of the 1370 cases receiving compensation during the study period, six females $(0.4 \%)$, as well as 51 individuals $(3.8 \%)$ for which the information on date of birth, residence or date of first exposure was not available, have been excluded from the follow-up.

The status of all the remaining 1313 members of the cohort as of 31 December 1984 has been ascertained through the mortality registries of the towns of residence. A copy of the death certificates was obtained for each decedent. The underlying cause of death was coded according to the eighth revision of the International Classification of Diseases (15). For $551(62.8 \%$ ) of the 878 deaths, the results of the postmortem examination were also available. For all but six of these persons, the diagnosis of silicosis was confirmed at autopsy. This finding indicates a high level of reliability for the criteria used in assigning compensation.

Information on smoking habits was available for 1225 workers $(93.3 \%)$. The number of cigarettes smoked daily was known for 889 of the 1064 smokers or ex-smokers $(83.6 \%)$. This information was reported in a direct interview with the worker when he applied for compensation. However, any changes that occurred in the smoking habits after the interview are not known.

Since the first report on the follow-up of this cohort (16), the files of an additional 69 individuals eligible for inclusion in the study have been discovered, and they have now been included in the study population. For a few individuals, incorrect dates of first exposure had to be modified, and there will be small differences in the distribution of the observed and expected deaths in any comparisons with the previous follow-up.

Lung cancer mortality in Italy is characterized by a wide geographic variability with an increasing gradient from the southern regions to the northern ones (3). As lung cancer mortality rates in the Veneto region are some $40 \%$ higher than national ones, both national and regional populations have been used as reference. Age-, sex- and five-year calendar-specific na- tional mortality rates were available for the period 1959-1980, and they were extended until December 1984 in order to cover the period of observation. Regional mortality rates were available only for two calendar periods, ie, 1967-1973 and 1974-1980. In order to cover the entire period of observation, the rates of the first period have been used for the period 1959-1973, and those of the second period were extended up to the end of the follow-up.

A modified life-table procedure and computing program (4) has been used for computing the personyears at risk, expected numbers of deaths, and standardized mortality ratios (observed/expected $\times 100$ ) for the period of observation 1959-1984. Ninety-five percent confidence intervals for the standardized mortality ratios have been computed on the assumption of a Poisson distribution.

Generalized linear interactive modelling (GLIM) (10) has been used for some aspects of the analysis of lung cancer mortality.

\section{Results}

During the observation period 878 deaths occurred among the 1313 members of the cohort, which contributed, for the same period, 23493.9 person-years at risk. The distribution of person-years by time since first exposure (table 1) clearly shows that the great majority of person-years occurred in the very long observation periods due to the criteria of inclusion in the cohort.

Table 2 reports the results of the mortality analysis during the overall period of observation by cause of death. Total mortality was significantly increased mainly due to the large excess of deaths from silicotuberculosis and silicosis.

Cancer mortality was also significantly in excess due to the twofold increase of lung cancer and to an excess of cancer of the upper respiratory and digestive tracts.

Six deaths from leukemia (3.0 expected) and one from lymphoma ( 3.5 expected) occurred. Gastrointestinal cancer was not found to be in excess.

Among the other causes of death only mortality from diseases of the digestive system presented a statistically significant increase. Thirty deaths from cirrhosis of the liver accounted for the entire excess.

In table 3 we present the causes of death of major interest analyzed by time since first exposure to silica

Table 1. Distribution of the person-years at risk and the number of deaths by time since first exposure during the followup, $1959-1984$.

\begin{tabular}{lcccccc}
\hline & \multicolumn{6}{c}{ Time since first exposure (years) } \\
\cline { 2 - 7 } & $\leq 9$ & $10-19$ & $20-29$ & $30-39$ & $\geq 40$ & Total \\
\cline { 2 - 7 } & 307.9 & 3457.0 & 7434.1 & 7206.8 & 5088.1 & 23493.9 \\
Person-years & 1 & 48 & 189 & 275 & 365 & 878 \\
Number of deaths & 1 & & &
\end{tabular}


Table 2. Mortality analysis by selected cause with the national mortality rates as reference for the expected $(E)$ number of deaths. The overall period of observation was 1959-1984. IO = observed number of deaths, SMR = standardized mortaiity ratio, $98 \% \mathrm{Cl}=95 \%$ confidence interval]

\begin{tabular}{lrrrr}
\hline Cause of death $^{2}$ & \multicolumn{1}{c}{$\mathrm{O}$} & $\mathrm{E}$ & $\mathrm{SMR}$ & $95 \% \mathrm{Cl}$ \\
\hline All causes & 878 & 408.7 & 215 & $201-230$ \\
Infectious diseases & 180 & 9.5 & 1903 & $1895-2193$ \\
(001-136) & & & & \\
$\quad$ Silicotuberculosis (010) & 175 & & & \\
Neoplasms (140-209) & 146 & 107.1 & 136 & $115-160$ \\
$\quad$ Buccal, pharynx (140-149) & 7 & 3.7 & 190 & $76-390$ \\
$\quad$ Esophagus (150) & 5 & 2.9 & 170 & $52-402$ \\
$\quad$ Digestive tract (151-154) & 18 & 27.4 & 66 & $39-104$ \\
$\quad$ Larynx (161) & 8 & 4.4 & 182 & $79-358$ \\
$\quad$ Lung (162) & 70 & 29.3 & 239 & $186-302$ \\
$\quad$ Leukemia (204-207) & 6 & 3.0 & 200 & $73-435$ \\
$\quad$ Lymphomas (200-203, & 1 & 3.5 & 28 & $1-159$ \\
$\quad$ All others & 31 & 32.9 & 94 & $64-134$ \\
Diseases of the circulatory & 181 & 169.8 & 107 & $92-123$ \\
system (390-458) & & & & \\
Diseases of the respiratory & 270 & 33.5 & 807 & $713-908$ \\
system (460-519) & 236 & & & \\
$\quad$ Silicosis (515) & & & & \\
Diseases of the digestive & 49 & 36.0 & 136 & $101-180$ \\
system (520-577) & 29 & 23.6 & 123 & $82-177$ \\
Accidents (800-999) & 23 & 29.3 & 79 & $50-118$ \\
\hline All others & &
\end{tabular}

a Code of the International Classification, eighth revision, in parentheses. dust. The standardized mortality ratio for all neoplasms increased with time since first exposure mainly due to the lung cancer mortality, which steadily increased reaching statistically significant excesses in the groups with $30-39$ and $\geq 40$ years since first exposure. The two major causes of deaths, namely silicotuberculosis and silicosis, were consistently elevated with no clear relationship with time since first exposure.

The relationship between lung cancer mortality and duration of exposure is shown in table 4 with both the national and regional rates for comparison. Workers exposed for 20 or more years to silica dust appear to be at higher risk than those in the categories with shorter exposure. This pattern contrasts with that of the two main causes of death (ie, silicotuberculosis and silicosis), for which there was an inverse relationship between duration of exposure and mortality (results not reported in tabular form).

All the standardized mortality ratios were equally reduced by some $30 \%$ when the regional population was used as a reference. As the regional population is likely to be more comparable to the study population, comparison with the national population has been omitted in tables 5 and 6.

Table 3. Mortality analysis by time since the subjects' first exposure and selected causes of death. The mortality of the national population has been used as reference. ( $\mathrm{O}=$ observed number of deaths, $\mathrm{E}=$ expected number of deaths, $\mathrm{SMR}=$ standardized mortality ratio, $95 \% \mathrm{Cl}=95 \%$ confidence interval)

\begin{tabular}{|c|c|c|c|c|c|c|c|c|c|c|c|c|c|c|c|}
\hline \multirow{3}{*}{$\begin{array}{l}\text { Years } \\
\text { since } \\
\text { first } \\
\text { expo- } \\
\text { sure }\end{array}$} & \multicolumn{15}{|c|}{ Cause of deatha } \\
\hline & \multicolumn{3}{|c|}{ Atl causes } & \multicolumn{3}{|c|}{ Infectious diseases } & \multicolumn{3}{|c|}{ Neoplasms } & \multicolumn{3}{|c|}{ Lung } & \multicolumn{3}{|c|}{$\begin{array}{l}\text { Diseases of the } \\
\text { respiratory system }\end{array}$} \\
\hline & O/E & SMR & $95 \% \mathrm{Cl}^{\mathrm{b}}$ & OIE & SMR & $95 \% \mathrm{Cl}^{\circ}$ & $\mathrm{O} / \mathrm{E}$ & SMR & $95 \% \mathrm{Cl}^{\mathrm{b}}$ & O/E & SMR & $95 \% \mathrm{Cl}^{\mathrm{b}}$ & $\mathrm{O} / \mathrm{E}$ & SMR & $95 \% \mathrm{Cl}^{\mathrm{b}}$ \\
\hline$\leq 9$ & $1 / 1.7$ & 58 & $0-328$ & $-/ 0.1$ & 0 & . & $1 / 0.4$ & 253 & . & -10.1 & 0 & . & -10.1 & 0 & . \\
\hline $10-19$ & $48 / 20.5$ & 234 & $173-310$ & $14 / 1.2$ & 1136 & $638-1958$ & $3 / 4.8$ & 62 & $13-183$ & -11.2 & 0 & $0-307$ & $10 / 1.3$ & 765 & $369-1415$ \\
\hline $20-29$ & $189 / 75.2$ & 251 & $218-291$ & $63 / 2.8$ & 2224 & $1729-2879$ & $24 / 19.8$ & 121 & $78-180$ & 715.3 & 131 & $53-272$ & $47 / 5.3$ & 879 & $652-1179$ \\
\hline $30-39$ & $275 / 125.3$ & 219 & $194-247$ & $56 / 2.8$ & 1967 & $1511-2597$ & $45 / 35.5$ & 127 & $92-170$ & $26 / 10.4$ & 250 & $163-366$ & $89 / 9.6$ & 927 & $745-1141$ \\
\hline$\geq 40$ & $365 / 186.0$ & 196 & $176-218$ & $47 / 2.4$ & 1932 & $1439-2604$ & $73 / 46.6$ & 157 & $123-197$ & $37 / 12.3$ & 300 & $212-415$ & $124 / 17.1$ & 725 & $582-839$ \\
\hline Total & $878 / 408.7$ & 215 & $201-230$ & $180 / 9.5$ & 1903 & $1628-2192$ & $146 / 107.1$ & 136 & $115-160$ & $70 / 29.3$ & 239 & $186-302$ & $270 / 33.5$ & 807 & $713-908$ \\
\hline
\end{tabular}

a Infectious diseases $=I C D 001-136$, neoplasms $=$ ICD 140-209, lung $=$ ICD 162, diseases of the respiratory system $=$ ICD $460-519$ (ICD $=$ International classification of diseases, eighth revision).

b The confidence interval was not computed if the expected number was less than 0.5

Table 4. Lung cancer mortality 20 or more years since the subjects' first exposure by duration of exposure. The mortality of both the national and regional populations have been used as reference. $(E=$ expected number of deaths, SMR $=$ standardized mortality ratio)

\begin{tabular}{|c|c|c|c|c|c|c|c|c|c|c|c|c|c|c|c|}
\hline \multirow{4}{*}{$\begin{array}{l}\text { Years } \\
\text { since } \\
\text { first } \\
\text { exposure }\end{array}$} & \multicolumn{15}{|c|}{ Duration of exposure (years) } \\
\hline & \multicolumn{5}{|c|}{$\leq 9$} & \multicolumn{5}{|c|}{$10-19$} & \multicolumn{5}{|c|}{$\geq 20$} \\
\hline & \multirow{2}{*}{ Otserved } & \multicolumn{2}{|c|}{ National rates } & \multicolumn{2}{|c|}{ Regional rates } & \multirow{2}{*}{ Observed } & \multicolumn{2}{|c|}{ National rates } & \multicolumn{2}{|c|}{ Regional rates } & \multirow{2}{*}{ Observed } & \multicolumn{2}{|c|}{ National rates } & \multicolumn{2}{|c|}{ Regional rates } \\
\hline & & $E$ & SMR & $E$ & SMR & & $E$ & SMR & $E$ & SMR & & $E$ & SMR & $E$ & SMR \\
\hline $20-29$ & 3 & 2.8 & 108 & 4.2 & 72 & 4 & 2.0 & 203 & 3.1 & 130 & - & 0.5 & 0 & 0.9 & 0 \\
\hline $30-39$ & 10 & 4.7 & $213^{*}$ & 6.3 & 159 & 9 & 4.1 & $219^{*}$ & 5.6 & 160 & 6 & 1.5 & $393^{*}$ & 2.2 & $274^{*}$ \\
\hline$\geq 40$ & 14 & 3.9 & $361^{*}$ & 5.1 & $274^{*}$ & 12 & 4.9 & $245^{\circ}$ & 6.5 & 185 & 11 & 3.4 & $321^{*}$ & 4.7 & $235^{*}$ \\
\hline Total & 27 & 11.4 & $237^{*}$ & 15.6 & $173^{*}$ & 25 & 11.0 & $227^{*}$ & 15.2 & $164^{*}$ & 17 & 5.4 & $315^{*}$ & 7.8 & $217^{*}$ \\
\hline
\end{tabular}

$=P<0.05$. 
Table 5. Lung cancer mortality 20 or more years since first exposure by type of exposure. The mortality of the regional population has been used as reference. $(O=$ observed number of deaths, $E=$ expected numbers of deaths, SMR $=$ standardized mortality ratio, $95 \% \mathrm{Cl}=95 \%$ confidence interval)

\begin{tabular}{|c|c|c|c|c|c|c|c|c|c|c|c|c|c|c|c|}
\hline \multirow{3}{*}{$\begin{array}{l}\text { Years } \\
\text { since } \\
\text { first } \\
\text { exposure }\end{array}$} & \multicolumn{15}{|c|}{ Type of exposure } \\
\hline & \multicolumn{3}{|c|}{ Mining } & \multicolumn{3}{|c|}{ Tunneling } & \multicolumn{3}{|c|}{ Quarrying } & \multicolumn{3}{|c|}{$\begin{array}{l}\text { Mixed mining, tun- } \\
\text { neling and quarrying }\end{array}$} & \multicolumn{3}{|c|}{ Other } \\
\hline & O/E & SMR & $95 \% \mathrm{Cl}$ & $\mathrm{O} / \mathrm{E}$ & SMR & $95 \% \mathrm{Cl}$ & O/E & SMR & $95 \% \mathrm{Cl}$ & $\mathrm{O} / \mathrm{E}$ & SMR & $95 \% \mathrm{Cl}$ & OIE & SMR & $95 \% \mathrm{Cl}$ \\
\hline $20-29$ & $2 / 2.2$ & 91 & $11-330$ & $2 / 2.9$ & 70 & $8-252$ & -10.4 & 0 & . & $2 / 2.0$ & 101 & $12-364$ & $1 / 0.7$ & 144 & $4-804$ \\
\hline $30-39$ & $5 / 3.6$ & 140 & $46-328$ & $9 / 5.2$ & 173 & $79-328$ & $3 / 0.4$ & 683 & $141-1993$ & $7 / 3.8$ & 182 & $73-371$ & $2 / 1.0$ & 209 & $25-754$ \\
\hline$\geq 40$ & $6 / 3.3$ & 185 & $68-402$ & $17 / 6.2$ & 274 & $160-438$ & $3 / 1.0$ & 294 & $61-860$ & $7 / 4.8$ & 146 & $59-300$ & $3 / 0.8$ & 359 & $74-1047$ \\
\hline Total & $13 / 9.6$ & 135 & $72-231$ & $28 / 15.0$ & 187 & $124-271$ & $6 / 1.9$ & 314 & $115-684$ & $16 / 11.2$ & 143 & $82-233$ & $6 / 2.7$ & 222 & $81-482$ \\
\hline
\end{tabular}

Table 6. Lung cancer mortality 20 or more years since first exposure by the subjects' daily consumption of cigarettes and their duration of exposure. The mortality of the regional population has been used as reference. $(0=$ observed number of deaths, $E=$ expected number of deaths, SMR = standardized mortality ratio, $95 \% \mathrm{Cl}=95 \%$ confidence interval)

\begin{tabular}{|c|c|c|c|c|c|c|c|c|c|c|c|}
\hline \multirow{3}{*}{ Smoking rate } & \multicolumn{11}{|c|}{ Duration of exposure (years) } \\
\hline & \multicolumn{3}{|c|}{$\leq 9$} & \multicolumn{3}{|c|}{$10-19$} & \multicolumn{2}{|c|}{$\geq 20$} & \multicolumn{3}{|c|}{ Total } \\
\hline & O/E & SMR & $95 \% \mathrm{Cl}$ & OIE & SMR & $95 \% \mathrm{Cl}$ & O/E & SMR $\quad 95 \% \mathrm{Cl}$ & OIE & SMR & $95 \% \mathrm{Cl}$ \\
\hline 0 cigarettes $/ \mathrm{d}$ & $0 / 2.3$ & 0 & $0-160$ & $1 / 1.9$ & 52 & $1-292$ & $3 / 0.9$ & $33870-987$ & $4 / 5.1$ & 79 & $21-201$ \\
\hline $1-9$ cigarettes/d & $7 / 4.4$ & 158 & $64-326$ & $7 / 4.7$ & 148 & $60-306$ & $5 / 2.3$ & $21470-500$ & $19 / 11.3$ & 168 & $100-289$ \\
\hline $\begin{array}{l}10-19 \\
\text { cigarettes/d }\end{array}$ & $8 / 4.3$ & 185 & $80-365$ & $12 / 4.9$ & 243 & $126-425$ & $5 / 2.1$ & $23777-552$ & $25 / 11.4$ & 220 & $142-325$ \\
\hline$\geq 20$ cigarettes $/ d$ & $5 / 1.1$ & 459 & $158-1134$ & $3 / 1.3$ & 228 & $47-666$ & $2 / 0.5$ & $38146-1376$ & $10 / 2.9$ & 348 & $164-628$ \\
\hline Total & $20 / 12.2$ & 165 & $101-256$ & $23 / 12.9$ & 179 & $113-268$ & $15 / 5.9$ & $256143-422$ & $58 / 30.9$ & 188 & $143-243$ \\
\hline
\end{tabular}

Table 5 shows the lung cancer mortality by type of exposure 20 or more years since first exposure. An elevated standardized mortality ratio is discernible in all the listed categories. Silicotics with exposure in quarries showed the highest overall standardized mortality ratio. All the ratios were however based on small numbers.

We also analyzed the lung cancer mortality in relation to the calendar periods in which the members of the cohort were first exposed to silica. No clear pattern was discernible apart from a decreased standardized mortality ratio (close to 100 when the regional reference population was used) for those entering after 1945. This finding is however difficult to interpret because of the shorter follow-up of this subgroup, and these results have not been presented.

Out of the 1225 members of the cohort with known smoking habits, $975(79.6 \%)$ were current smokers at the time of the claim for compensation, $89(7.3 \%)$ were ex-smokers, and only $161(13.1 \%)$ had never smoked. The results of the analysis by smoking habits indicate that the excess risk for lung cancer was concentrated among current smokers ( 59 observed versus 22.1 expected, standardized mortality ratio 268 ).

Table 6 presents the results of the analysis of the lung cancer mortality by the amount of smoking and the duration of exposure to silica. The ex-smokers were assigned to the cigarette smoking category correspond- ing to their reported previous consumption. The exclusion from the analysis of 262 individuals with an unknown level of smoking and eight without duration of exposure accounts for the slight differences from the previous tables.

No clear synergistic effect between the smoking and silica exposure was discernible, whereas an increasing pattern was present for lung cancer mortality with an increasing level of smoking within the exposure categories, the magnitude of risk being largest in the category with the longest duration of exposure. The effect of the two variables (level of smoking and duration of exposure) have formally been tested with GLIM (10). Both variables were independently associated with an increase in the standardized mortality ratio for lung cancer. The association was statistically significant $(\mathbf{P}<0.01)$ for smoking but not for duration of exposure $(P=0.2)$. A multiplicative model poorly fit the data with a significant negative interaction term for the highest exposure and smoking categories. The effect of each factor was only evident in the lower exposure categories of the other.

\section{Discussion and conclusions}

The evidence of a lack of association between silicosis and lung cancer has been mainly based on findings 
from an autopsy series in which the frequency of lung cancer in silicotics was compared to that in nonsilicotics (13). Recent studies in Sweden, the United States, Finland, and Italy provide new evidence of a positive association between silicosis and lung cancer $(5,8,11$, $12,16)$. All these studies reported an elevated overall mortality, mainly due to nonmalignant respiratory diseases and to tuberculosis or silicotuberculosis.

The results of our study confirm these earlier findings. Our cohort exhibited a large mortality excess due to silicotuberculosis and silicosis. More than $50 \%$ of the deaths were due to these two causes, and there was no relationship with duration or type of exposure or with smoking habits.

Lung cancer mortality was elevated, and the results from autopsies indicated that it could well have been underestimated. Twenty-two lung cancer cases not reported on the death certificates were found by postmortem examination, while only six lung cancers reported on the death certificates were not confirmed at autopsy.

The lung cancer excess was only slightly associated with duration of exposure (although it showed a clear relationship among nonsmokers and light smokers). Workers with the longest duration of exposure experienced the lowest mortality from silicotuberculosis and silicosis and the highest mortality from lung cancer. This finding suggests that the risk for lung cancer is difficult to detect when it is competing with the high risk of dying from silicotuberculosis and silicosis. The most severe cases of silicosis, in fact, have often been associated with relatively short periods of exposure to very high levels of silica dust.

Occupations in mines, tunnels, and foundries involve potential exposure to other well-known carcinogens, eg, radon daughters and polycyclic aromatic hydrocarbons. The possible contributing role of other occupational carcinogens such as these cannot be ruled out in our study.

The analysis by date of first exposure to silica was suggestive of a decrease in the standardized mortality ratio for lung cancer among those employed during the more recent work conditions. This apparent effect might partly be due to the shorter follow-up of the late entrants in that neither of the two major causes of death due to silica exposure showed a downward trend with time of starting exposure.

Although smoking in our study population was associated with the lung cancer excess, the magnitude of the risk was such as not to be readily explained by the effect of tobacco alone, even with the use of a regional reference population, which should have had characteristics closer to the population under study. Among the members of the cohort for whom the tobacco consumption was known, $15.4 \%$ had never smoked, $73.8 \%$ were light smokers, and $10.8 \%$ were heavy smokers (at least one pack per day). Similar data were not available for the Veneto region for the entire study period. However, the distribution of smoking habits in the Veneto population according to the 1980 census (9) were the following: $41.7 \%$ never smokers, $50.9 \%$ light smokers, and $7.4 \%$ heavy smokers. The application of the model suggested by Axelson (2) to our data shows that the difference in the smoking habits between the study population and the reference population should account for a $39 \%$ excess of lung cancer among silicotics, as compared to the $70.4 \%$ found.

Consideration should also be given to the fact that the expected values were computed on the basis of the lung cancer rates of the general population, which is constituted of both smokers and nonsmokers. According to Saracci (13) the expected values for nonsmokers should be reduced by a factor of at least 4 when the possible effect of other exposures is being investigated. After the application of this adjustment, the standardized mortality ratios for nonsmokers would present a three- to fourfold excess for lung cancer, depending on the reference population used. Although these estimates are based on small numbers and might well be affected by misclassification, they are however suggestive of the presence of a risk factor for lung cancer in addition to smoking.

A possible interpretation could be that silicosis itself, being a progressive disease, may predispose to the development of the neoplasia. Archer and his colleagues (1), in a follow-up study of uranium miners, found a higher frequency of bronchogenic cancer among miners with $\mathrm{X}$-ray findings of pneumoconiosis as compared to those without and suggested that pneumoconiosis may increase lung susceptibility to cancer. Studies on silicotic and nonsilicotic workers previously exposed to silica dust are warranted to test this hypothesis.

Only silicotics were enrolled in our study population and therefore the results cannot be interpreted in terms of a causal relationship between lung cancer and exposure to silica dust, although the lung cancer mortality tended to increase slightly with duration of exposure.

In conclusion, the results of this study indicate, in accordance with other studies, that silicosis is a pathological condition entailing an extremely high mortality risk, one that is also associated with a higher risk of lung tumors.

\section{Acknowledgments}

We would like to thank Dr R Saracci, Chief of the Unit of Analytical Epidemiology, International Agency for Research on Cancer (IARC) Lyon, for his invaluable help both in planning the study and in the discussion of the results, Mr AC Fletcher for his comments and his advice on the statistical analysis, and Ms A Zitou$\mathrm{ni}$ for the editorial work. Both Mr Fletcher and Ms Zitouni are also from IARC.

The study was supported by the Italian National Research Council. 


\section{References}

1. Archer VE, Gillam JD, Wagoner JK. Respiratory disease mortality among uranium miners. Ann NY Acad Sci 271 (1976) 280-293.

2. Axelson $\mathrm{O}$. Aspects on confounding in occupational health epidemiology. Scand J Work Environ Health 4 (1978) 98-102.

3. Capocaccia R, Farchi G, Mariotti S, Verdecchia A, Angeli A, Morganti P, Panichelli Fucci ML. La mortalita in Italia nel periodo 1970-79. Rapporti Istisan, Rome 1984.

4. Coleman M, Douglas A, Hermon C, Peto J. Cohort study analysis with a fortran computer program. Int $\mathbf{J}$ Epidemiol 15 (1986) 134-137.

5. Finkelstein MM, Muller J, Kusiak R, Suranyi G. Followup of miners and silicotics in Ontario. In: Goldsmith DF, Winn DM, Shy CM, ed. Silica, silicosis, and cancer: Controversy in occupational medicine. Praeger Publishers, New York, NY 1986, pp 321-325. (Cancer research monographs, volume 2).

6. Goldsmith DF, Guidotti TL, Johnson DR. Does occupational exposure to silica cause lung cancer? Am J Ind Med 3 (1982) 423

7. Heppleston AG. Silica, pneumoniosis, and carcinoma of the lung. Am J Ind Med 7 (1985) 285-294.

8. Kurppa K, Gudbergsson H, Hannunkari I, Koskinen H, Hernberg S, Koskela RS, Ahlman K. Lung cancer among silicotics in Finland. In: Goldsmith DF, Winn DM, Shy $\mathrm{CM}$, ed. Silicà, silicosis, and cancer: Controversy in occupational medicine. Praeger Publishers, New York, NY 1986, pp 311-319. (Cancer research monographs, vol- ume 2).

9. Regione Veneto. Servizio elaborazione sistemi informativi: Indagine sulle condizioni di salute della popolazione. Venezia 1985.

10. Royal Statistical Society. Generalized linear interactive modelling. Oxford 1978.

11. Rubino GF, Scansetti G, Coggiola M, Pira E, Piolatto G, Coscia GC. Studio epidemiologico di mortalità in una coorte di silicotici nella regione Piemonte. In: Cooperativa Libraria Editrice Universita di Padova. Silice, silicosi e cancro. Padova 1985, pp 121-132.

12. Ruttner JR. Silicosis and lung cancer in Switzerland. Schweiz med Wochenschr 99 (1969): 8, 245-249.

13. Saracci R. Asbestos and lung cancer: An analysis of the epidemiological evidence on the asbestos-smoking interaction. Int J Cancer 20 (1977) 323-331.

14. Westerholm P. Silicosis: Observations on a case register. Scand J Work Environ Health 6 (1980): suppl 2, $86 \mathrm{p}$.

15. World Health Organization. International classification of diseases. 1965 Revision. Volume I. Geneva 1967.

16. Zambon $P$, Simonato L, Mastrangelo R, Winkelmann R, Saia B, Crepet M. A mortality study of workers compensated for silicosis during 1959 to 1963 in the Veneto region of Italy. In: Goldsmith DF, Winn DM, Shy CM, ed. Silica, silicosis and cancer: Controversy in occupational medicine. Praeger Publishers, New York, NY 1986, pp 367-374. (Cancer research monographs, volume 2).

Received for publication: 2 June 1986 